\title{
Functionalization of cotton with poly-NiPAAm/chitosan microgel. Part I. Stimuli-responsive moisture management properties
}

\author{
Pavla Križman Lavrič • \\ Marijn M. C. G. Warmoeskerken • \\ Dragan Jocic
}

Received: 21 December 2010/ Accepted: 24 November 2011 / Published online: 3 December 2011

(C) The Author(s) 2011. This article is published with open access at Springerlink.com

\begin{abstract}
Stimuli-responsive microgel, based on synthetic polymer (poly-NiPAAm) and biopolymer (chitosan), was incorporated onto cotton fabric surface by pad-dry-cure method using 1,2,3,4-butanetetracarboxylic acid (BTCA) as crosslinker. In order to assess the moisture management properties of cotton functionalized with responsive microgel, the effects of temperature, relative humidity and concentration of microgel on water vapour transmission rate (WVTR) and moisture content (MC) were quantified. Since the use of experimental design is considered as a highly attractive feature in dealing with experiments and variables of this nature, the effects were quantified by using a central composite design. The regression equations obtained from the statistical analysis allowed the prediction of WVTR and MC at different ambient conditions. Material properties such as crease recovery and whiteness were also measured. The results indicate that both relative humidity and temperature significantly influence studied responses (WVTR and MC), showing that good perspiration can be achieved at lower humidity levels and at higher temperatures. The observed phenomena are attributed
\end{abstract}

P. Križman Lavrič · M. M. C. G. Warmoeskerken .

D. Jocic $(\bowtie)$

Engineering of Fibrous Smart Materials (EFSM),

Faculty of Engineering Technology (CTW),

University of Twente, Enschede, The Netherlands

e-mail: D.Jocic@utwente.nl to controlled expansion (or contraction) of the surface incorporated microgel, which acts as a sensor of temperature and as a valve to regulate the water vapour permeability of functionalized cotton.

Keywords Cotton - Stimuli-responsiveness · Microgel · Poly-NiPAAm · Chitosan · Moisture management

\section{Introduction}

As a consequence of a modern lifestyle, performance apparel production represents today one of the fastest growing sectors of the textile industry. It is a typical high added-value textile product that provides consumers with greater levels of comfort, safety, aesthetics and functional performance. Good thermal sensation and comfort are key factors for the production of performance apparel, both being related to the ability of the fabric to maintain thermal equilibrium between the human body and the environment, which is influenced by moisture and liquid management abilities of the material ( $\mathrm{Li}$ 2001). Since one of the main functions of clothing is insulation, it has to support thermoregulation, so the interaction of human body functions with clothing currently gains great importance (Hipler and Elsner 2006). Adaptive functions of textiles should be capable of supporting the abrupt microclimate changes, especially during 
exercise or in extreme environmental (cold and heat) conditions (Wollina et al. 2006).

Due to its soft hand, high hydrophilicity (absorbing moisture and sweat) and breathability, cotton is generally considered as the most comfortable textile material for most end uses. Nevertheless, even though it is one of the most versatile fibres which is being very important in the production of apparel, there are very few, if any, garments made of $100 \%$ cotton fabric that are considered as performance apparel. This is the consequence of certain issues on cotton (too heavy when wet; too long drying; the wearer often feels cold after the activity ends) which are considered as disadvantages for performance apparel. Moreover, being such a traditional fibre, cotton is not generally perceived and advertised as an advanced material when competing modern synthetic fibres. Hence, innovation and enhancement must take place for cotton material to satisfy the demands for performance apparel products.

Since the actual trend in producing textile materials is to ensure "smart" capability of interacting with human/ environmental conditions (Mattila 2006), it is necessary to consider further development of materials for performance apparel with stimuli-responsive ability. The specific attribute (function or effect) of such a material could be activated "on demand" by sensing the stimuli in immediate surrounding environment and reacting to the human/environmental conditions. In practice, this means that the material itself can sense, react and adapt to the temperature and humidity conditions provided by the activity level of the wearer and/or environmental conditions, by managing correspondingly moisture and liquid passage through the material.

Initial attempts to provide cotton with thermal adaptability included binding of polyethylene glycols to cotton utilizing a polyfunctional crosslinking agent (Bruno and Vigo 1987; Vigo et al. 1992; Vigo 1997). It has been confirmed that the resultant fabrics release heat when the temperature drops and absorb heat when the temperature rises. More recent approach includes the incorporation of phase change materials (PCMs) in textiles by coating or encapsulation to make thermoregulated smart textiles (Mondal 2008). Since PCMs possess the ability to change their state with a certain temperature range, when incorporated to textile material they take advantage of latent heat that can be stored or released from a material over a narrow temperature range. Microencapsulated PCMs can be incorporated onto cotton fabric by using polyurethane binder to produce a small temporary cooling effect in a transition from a cold environment to a warm environment (Salaün et al. 2010).

It has been shown previously that the use of a surface modifying system, prepared from dual-stimuli responsive microgel, could impart responsive moisture management properties to cotton, transforming it to an advanced material (Jocic et al. 2009). Stimuli-responsive microgel can be obtained by aqueous copolymerization of $\mathrm{N}$-isopropylacrylamide (NiPAAm) with water soluble polymers containing amino groups, such as chitosan (Lee et al. 2003). Poly-NiPAAm is a wellknown thermo-responsive polymer which shows a coil to globule transition at the temperature around $32{ }^{\circ} \mathrm{C}$ (lower critical solution temperature-LCST) (Schild 1992). Macroscopically, this transition is perceived as a change from hydrophilic to hydrophobic state when the temperature rises above LCST. Since its LCST value falls between human body temperature and ambient temperature, poly-NiPAAm is particularly suitable for the development of smart materials for clothing applications (Crespy and Rossi 2007). On the other hand, chitosan is a biopolymer which responds to the changes in the $\mathrm{pH}$ of the surrounding medium by hydration/dehydration which is macroscopically observable as swelling/de-swelling response, especially when it is in the form of hydrogel (Rinaudo 2006). The response is triggered by the presence of functional amino groups which get ionized and acquire a positive charge in acidic medium. Our previous study (Kulkarni et al. 2010) reported on the transition temperature (LCST) of poly-NiPAAm/chitosan (PNCS) microgel in aqueous system by measuring the absorbance of the microgel dispersion (UV-Vis spectrophotometry) and microgel particle hydrodynamic size (DLS measurements) as a function of $\mathrm{pH}$ and temperature. The results showed that at $\mathrm{pH} 2$ the transition temperature can be estimated as $26{ }^{\circ} \mathrm{C}$, at $\mathrm{pH} 4$ it was around $30^{\circ} \mathrm{C}$ and at $\mathrm{pH} 7$ and $\mathrm{pH} 9$ it was $33^{\circ} \mathrm{C}$. These measurements confirmed the dual ( $\mathrm{pH}$ and temperature) responsiveness of the microgel particles, as well as the fact that the transition temperature (LCST) of the microgel decreases with decrease in $\mathrm{pH}$.

Even though it is considered an important property, $\mathrm{pH}$-responsiveness of chitosan (and microgel made of it) is not the subject of this study, but it will be considered in a subsequent part of the study which will deal with liquid 
management properties (Krizman Lavric et al. 2011). Nevertheless, combining chitosan as a product of natural origin with a synthetic polymer like poly-NiPAAm, imparts certain advantages to the surface modifying system, such as biocompatibility and providing active sites for subsequent crosslinking with cotton.

Poly-NiPAAm/chitosan (PNCS) microgel can be incorporated onto cotton by a pad-dry-cure process, using 1,2,3,4-butanetetracarboxylic acid (BTCA) as crosslinker (Kulkarni et al. 2010). During curing, carboxylic groups of BTCA can react with hydroxyl groups from both cotton and chitosan by forming stable ester bonds, possibly reacting also with free amino groups of chitosan via formation of amide (Sauperl et al. 2009; El-tahlawy et al. 2005).

In order to keep the wearer dry and comfortable during sweating the vapour from sweat must be transmitted through the porous structure of modified cotton towards the outer layer where it evaporates. This makes the wearer feel dry and comfortable (Li 2001; Männer et al. 2004; Okubayashi et al. 2005). In order to improve the wearer comfort, the modified cotton with incorporated microgel should possess high water vapour permeability at higher temperature and low water vapour permeability at lower temperature. Since PNCS microgel particles are confirmed to exhibit a reversible phase transition (expansioncontraction) by varying their size more than threefold between temperature above and below LCST (Kulkarni et al. 2010), once incorporated to cotton surface it is likely that they act as a sensor of temperature and as a valve to regulate the water vapour permeability of cotton. Thus, functionalized cotton fabric could have water vapour permeability controlled by closing and opening the permitting passages for water vapour transport through the material as the consequence of the drastic size change of microgel particles with the variation of temperature. Therefore, the main property of interest in the present paper is water vapour permeability of the modified material, which is measured by the water vapour transmission rate (WVTR). However, the transport through hygroscopic porous materials is a complex phenomenon, due to the tendency of fibres to take-up water vapour and experience swelling that can close-off the pores in the fabric. Therefore, moisture content (MC) measurements were performed in parallel with WVTR.

Currently, a number of test methods are available to quantify the water vapour transport through textile materials, ranging from sophisticated methods like guarded hot plate (GHP) apparatus and dynamic moisture permeation cell (DMPC) to more simple ones where a conventional dish or cup method is used (Indushekar et al. 2005; Das et al. 2007; Huang and Qian 2008; McCullough et al. 2003). Even though existing methods cannot be simply correlated as the consequence of being specifically related to the actual end-use of the material, they are successfully applied when WVTR of fabrics (and membranes) treated with different finishes and coatings needs to be measured. Up to date, only few reports are available on WVTR testing of materials with surface incorporated hydrogels. Nevertheless, the moisture permeability of wound dressings containing hydrogels (Balakrishnan et al. 2005), temperature-sensitive composite membranes (Huang et al. 2008) and shape memory polyurethane (SMPU) coated cotton fabrics (Mondal and $\mathrm{Hu} 2007$ ) were extensively studied by measuring the WVTR across the material using a cup method.

In order to provide a simulation of real climate conditions affecting water vapour permeability (i.e. thermal comfort) of cotton with incorporated PNCS microgel, a wider range of test conditions need to be studied, which can be time consuming. Since the use of experimental design is confirmed to be a highly attractive feature in dealing with experiments and variables of this nature, the effects of temperature, relative humidity and concentration of poly-NiPAAm/ chitosan microgel on the responsive moisture management properties (WVTR and MC) of the surface modified cotton were investigated in this study following a central composite response surface design which is recognized as an easy-to-use tool for process optimization (Box and Draper 1987; Myers et al. 2009). The regression equations obtained from the statistical analysis allowed the prediction of WVTR and MC at different ambient conditions. Material properties such as crease recovery and whiteness were also measured.

\section{Experimental}

\section{Materials}

Cotton fabric (100\% cotton plain fabric of $105 \mathrm{~g} / \mathrm{m}^{2}$ weight per unit area, desized, double scoured) was supplied by Vlisco (The Netherlands). Nonionic 
detergent Tanaterge EP5071 was supplied by Tanatex (The Netherlands). $N$-isopropylacrylamide (NiPAAm) monomer (Acros Organics, Belgium) was recrystallized from hexane before use. Chitosan (Chitoclear, $\mathrm{DD}=95 \%, \eta=159 \mathrm{mPa}$ s) was purchased from Primex (Iceland). Crosslinker ( $N, N$-methylenebisacrylamide (MBA)), initiator (ammonium persulfate (APS)), 1,2,3,4-butanetetracarboxylic acid (BTCA) and sodium hypophosphite (SHP) were purchased from Sigma-Aldrich (The Netherlands). All other chemicals used in the experimental work were of analytical grade.

\section{Preparation of poly-NiPAAm/chitosan (PNCS) microgel}

Chitosan solution was prepared by dissolving $1.0 \mathrm{~g}$ of chitosan in $300 \mathrm{~mL}$ of distilled water containing $3 \mathrm{~mL}$ of glacial acetic acid, and then stirred for $24 \mathrm{~h}$ at room temperature. NiPAAm/chitosan copolymerization was carried out in a three-neck round-bottom flask, equipped with condenser, mechanical stirrer and nitrogen inlet (Lee et al. 2003; Kulkarni et al. 2010). The flask was filled with chitosan solution and degassed with nitrogen during $30 \mathrm{~min}$. Subsequently, $7 \mathrm{~g}$ of NiPAAm and $0.21 \mathrm{~g}$ of MBA were added with vigorous stirring $(320 \mathrm{rpm})$, the temperature was raised to $50{ }^{\circ} \mathrm{C}$ and, after $40 \mathrm{~min}, 0.9 \mathrm{~g}$ of APS was added to initiate the polymerization. The reaction medium turned turbid after $5 \mathrm{~min}$ and the reaction was allowed to proceed for $3 \mathrm{~h}$ at $50{ }^{\circ} \mathrm{C}$ in the nitrogen atmosphere. In order to remove the unreacted monomer and oligomeric impurities, the reaction solution was dialysed (4 Spectra/Por, Fisher Scientific) against deionised water for at least 1 week.

In the reaction system of dispersion copolymerization there are several kinds of possible interactions between chitosan and poly-NiPAAm, such as electrostatic and hydrogen interactions (between chitosan amino groups and poly-NiPAAm amide functions), as well as covalent bonding due to the formation of radicals. The radical degradation of chitosan is the decisive step in the mechanism of copolymerization reaction (Hsu et al. 2002). Nevertheless, it has been shown (Harish Prashanth and Tharanathan 2003) that in free radical initiated copolymerization, $\mathrm{NH}_{2}$ groups of chitosan were involved in microradical formation, which can interact with electrophilic functional group to create covalent bonding. In addition, Liu et al.
(2007) stated that in the chemical structure of the grafting copolymers poly-NiPAAm was attached to the $\mathrm{C}_{6}-\mathrm{OH}$ reactive group of chitosan and to amine group. In summary, the covalent bonding between chitosan and poly-NiPAAm can be created from different chitosan functional groups: the terminal carbonyl groups of its backbone, its amino functions or its $\mathrm{C}_{6}-\mathrm{OH}$ reactive groups. The possibility of anionic persulfate (from the initiator) immobilization inside degraded chitosan chains through electrostatic attraction has been also mentioned (Hsu et al. 2002). Hence, chitosan plays multiple roles in the reaction system: in one way it can increase the polymerization rate by serving as a surfactant; on the other hand, the degraded chitosan chain can inhibit the free radicals and slow down the polymerization. The schematic representation of the PNCS microgel synthesis mechanism is given in our previous publication (Jocic et al. 2010a). The microgel of poly-NiPAAm and chitosan (PNCS), prepared by the above explained surfactantfree dispersion copolymerization method, consist of particles of homogeneous spherical shape, with quite narrow particle size distribution of $180 \mathrm{~nm}$ in dry state (Jocic et al. 2009; Tourrette et al. 2009).

Incorporation of poly-NiPAAm/chitosan microgel onto cotton surface (Co-PNCS/BTCA)

Before any further treatment, all cotton samples were washed in an aqueous solution containing $2 \mathrm{~g} / \mathrm{L}$ of Tanaterge EP5071 with liquor to goods ratio of 1:25 at $60{ }^{\circ} \mathrm{C}$ for $45 \mathrm{~min}$. After washing, the samples were rinsed twice, first in hot water and than in cold water, and dried at room temperature for $24 \mathrm{~h}$. Cotton fabric functionalization (Co-PNCS/BTCA) has been done by incorporating microgel dispersion (PNCS) in the presence of film forming agent (BTCA), using paddry-cure process. The finishing bath consisted of PNCS microgel dispersion (18 g/L) as well as BTCA and SHP in the ratios: PNCS:BTCA $=3.75: 1$; BTCA:SHP $=2: 1$. At first, BTCA was added into PNCS dispersion, after 5 min SHP (catalyst) was added and the bath was stirred for $5 \mathrm{~min}$. Then the cotton fabric sample was immersed with continued stirring for another $5 \mathrm{~min}$. Samples were then squeezed to a wet pickup of approximately 100, 150 or $200 \%$ using a laboratory padder to reach a desired concentration of PNCS microgel on cotton according to the statistical design, and dried at $70{ }^{\circ} \mathrm{C}$ for $1 \mathrm{~h}$. 
Finally, after curing at $160{ }^{\circ} \mathrm{C}$ for $3 \mathrm{~min}$, the samples were washed in the same manner as previously described and air dried.

When cotton fabric is treated with PNCS/BTCA reaction mixture, at first-due to absorptive property cotton-it adsorbs hydrophilic BTCA and PNCS microgel particles. Since there are two types of hydroxyl groups available for reaction with BTCA (hydroxyl groups of cotton cellulose and hydroxyl groups of chitosan from PNCS microgel particles), it is expected that BTCA crosslinking occurs via esterification with these hydroxyl groups as well as via formation of amide with free amino groups of chitosan (Fig. 1).

When BTCA is heated at high temperature, a fivemembered cyclic anhydride intermediate forms (Yang 1993), which is a reactive intermediate and readily esterifies when reaction sites are available. Several studies have shown that cellulosic esterification by polycarboxylic acids takes place in two phases. In the first phase a cyclic anhydride is formed (Yang et al. 1998), which forms an ester with the hydroxyl group $(-\mathrm{OH})$ in the cellulose macromolecule (Orhan et al. 2009; Sauperl and Stana-Kleinschek 2010). This is followed by formation of a second anhydride that subsequently reacts with another cellulose hydroxyl. However, in the presence of SHP, a second mechanism can occur, resulting in formation of a mixed linear anhydride (Gillingham et al. 1999). The number of covalent bonds or linkages which can be formed with cellulose is limited to one less than the number of carboxyl groups in the polycarboxylic acid (Bischof Vukusic and Katovic 2000). Since BTCA can form at least two ester bonds, two macromolecules can be crosslinked effectively (Xu and Shyr 2000). It has been reported (El-tahlawy et al. 2005) that under the action of heat during the curing step, part of BTCA can be consumed for linking chitosan to the cellulosic substrate through esterification. A formation of a covalent bond between the crosslinking agent, chitosan and cellulosic chains was confirmed (Hsieh et al. 2006; Shin and Ueda 1999). Moreover, esterification or amidation with $-\mathrm{OH}$ or $-\mathrm{NH}_{2}$ groups of chitosan can occur, if two $-\mathrm{COOH}$ groups remain available (El-tahlawy et al. 2005; Hsieh et al. 2006).

\section{Experimental design}

In order to assess moisture management performance of functionalized cotton (Co-PNCS/BTCA), water vapour permeability (WVTR) and moisture content (MC) were measured. An optimal approach to characterize the external factors affecting WVTR and MC is by using designed experiments. Using the central composite design generated by Design-Expert software (v. 6.0.8., Stat-Ease, Inc., USA), a set of 20 trials was run, including 8 factorial points, 6 axial points and 6 replicates at the centre point for estimation of the experimental error. Three factors were chosen as independent variables: (factor A) concentration of
Fig. 1 Proposed mechanism of PNCS crosslinking on cotton using BTCA

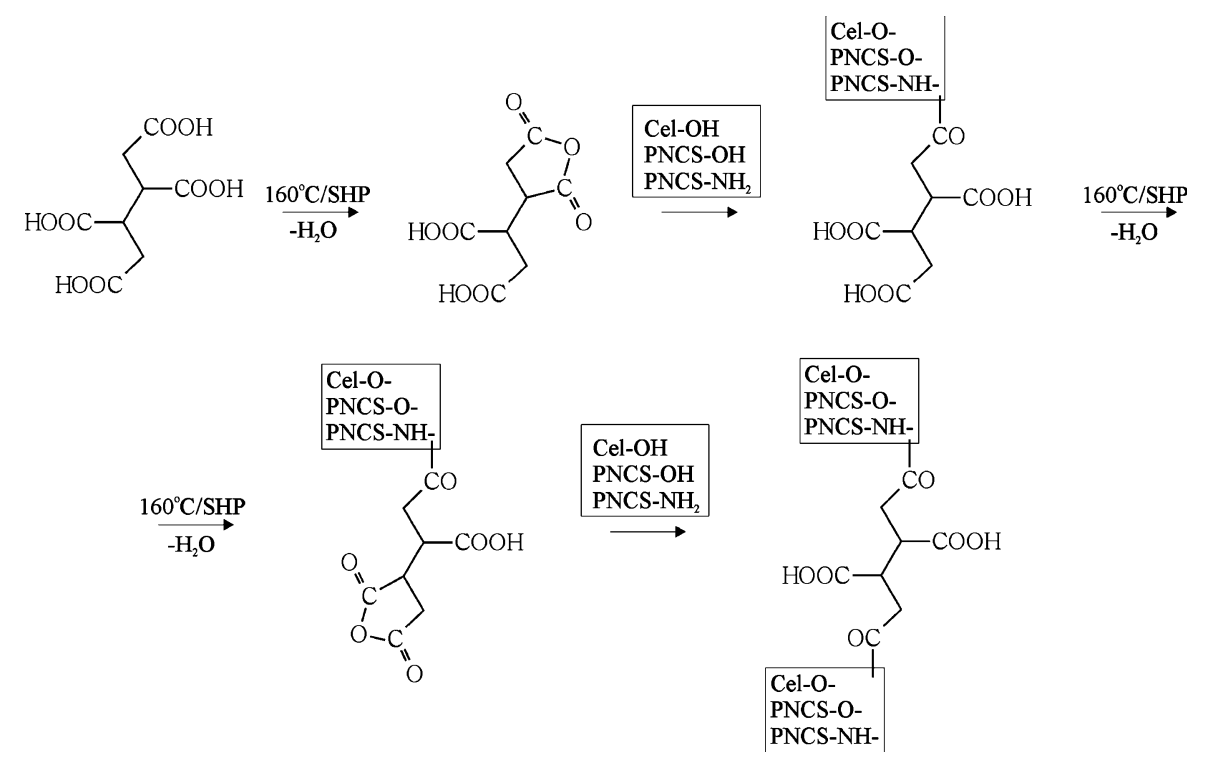


Table 1 Coded and actual values of independent variables used in the central composite design experiment

\begin{tabular}{llcrcrc}
\hline Factor & Variable & \multicolumn{5}{c}{ Level } \\
\cline { 3 - 7 } & & -2 & -1 & 0 & +1 & +2 \\
\hline A & PNCS (\% owf) & 0 & 1 & 2 & 3 & 4 \\
B & T ( ${ }^{\circ}$ C) & 17.5 & 25 & 32.5 & 40 & 47.5 \\
C & R.H. (\%) & 35 & 50 & 65 & 80 & 95 \\
\hline
\end{tabular}

PNCS microgel (\% owf); (factor B) temperature (T, ${ }^{\circ} \mathrm{C}$ ); and (factor $\mathrm{C}$ ) ambient relative humidity (R.H., $\%)$. Each factor included five levels $(-2,-1,0,+1$, +2 ), as shown in Table 1 .

The actual value of the centre point for the PNCS concentration (factor A, 2\% owf) has been chosen based on previously established requirement that for best results no more than $50 \%$ of the fibre surface should be covered by microgel (Jocic et al. 2010b). The choice of actual values for temperature (factor B) has been made based on the known fact that the transition point of PNCS microgel in slightly acidic or neutral aqueous system is estimated between 32 and $33{ }^{\circ} \mathrm{C}$ (Kulkarni et al. 2010). Therefore the temperature of $32.5{ }^{\circ} \mathrm{C}$ has been chosen for the centre point. The choice of actual values for relative humidity (factor $\mathrm{C}$ ) has been done in such a manner to cover wide range of ambient relative humidity, from dry (35\% R.H.) to very humid (95\% R.H.) environment, with the centre point at $65 \%$ R.H. which is considered as "standardized" ambient humidity for textile purposes.

The Design-Expert software has been used for statistical analysis and graph plotting. The effect of independent variables on the responses was determined by analysis of variance (ANOVA), where $p$ values lower than 0.05 were considered to be statistically significant. The response was predicted through a second-order polynomial equation as shown in Eq. 1:

$$
\begin{aligned}
\mathrm{Y}= & \beta_{0}+\beta_{1} \mathrm{X}_{1}+\beta_{2} \mathrm{X}_{2}+\beta_{3} \mathrm{X}_{3}+\beta_{11} \mathrm{X}_{1}^{2}+\beta_{22} \mathrm{X}_{2}^{2} \\
& +\beta_{33} \mathrm{X}_{3}^{2}+\beta_{12} \mathrm{X}_{1} \mathrm{X}_{2}+\beta_{13} \mathrm{X}_{1} \mathrm{X}_{3}+\beta_{23} \mathrm{X}_{2} \mathrm{X}_{3}
\end{aligned}
$$

where $\mathrm{Y}$ is the predicted response; $\beta_{0}$ is the intercept; $\beta_{1}, \beta_{2}$ and $\beta_{3}$ are linear coefficients; $\beta_{11}, \beta_{22}$ and $\beta_{33}$ are squared coefficients; $\beta_{12}, \beta_{13}$ and $\beta_{23}$ are interaction coefficients; and $\mathrm{X}_{1}, \mathrm{X}_{2}$ and $\mathrm{X}_{3}$ are independent variables (in our case factors $\mathrm{A}, \mathrm{B}$ and $\mathrm{C}$ ).

By using Eq. 1 not only the prediction of the response can be obtained but also the linear, quadratic and interactive effects of the independent variables on the response can be evaluated. To evaluate how each independent variable influenced the final response, we looked at coefficient estimates of these variables. If coefficient estimates were positive, a proportional effect should be observed, e.g. the final response increasing (or decreasing) after independent variable increase (or decrease). In contrast, if the coefficient estimates were negative, an inversely proportional effect should be the result, e.g. the final response increasing (or decreasing) after independent variable decrease (or increase).

Contour plots were used to graphically represent the relationship and interactions between independent and dependent variables (responses).

\section{Characterization methods}

Water vapour permeability (WVTR)

Water vapour permeability was measured according to the standard UNI 4818-26 used for fabrics coated with polymers. The method uses aluminium pots with covers which have an opening of $1,000 \mathrm{~mm}^{2}$ for water vapour exhaust through the textile fabric sample during testing. Three pots were filled with $25 \mathrm{~mL}$ of distilled water, a rubber gasket and a fabric sample were positioned and the pot was closed. In order to maintain the desired measurement conditions (temperature and relative humidity, Table 2), a climatic chamber (SM-1.0-3800, Thermotron, USA) has been used. Weight of the pots was recorded before introducing them into the climatic chamber and after remaining $24 \mathrm{~h}$ in the climatic chamber under specified conditions. The difference in weight, before and after $24 \mathrm{~h}$, corresponds to the quantity of water that was transmitted through the fabric as vapour. The water vapour transmission rate (WVTR) (Eq. 2) is expressed in grams (of vapour transmitted) per square meter (of fabric) in a day $(24 \mathrm{~h})$, and represents an average of three readings.

$\mathrm{WVTR}=\frac{\Delta m \times 24}{S \times t}$

where WVTR is the water vapour transmission rate $\left(\mathrm{g} \mathrm{m}^{-2}\right.$ day $\left.^{-1}\right) ; \Delta m$ is the weight change $(\mathrm{g}) ; S$ is the testing area of the fabric sample $\left(\mathrm{m}^{2}\right)$ (actual value $=1,000 \mathrm{~mm}^{2}$ ); $t$ is the testing time (h) (actual value $=24 \mathrm{~h}$ ). 
Table 2 Central composite design with three independent variables (actual levels) in various runs and experimentally obtained values for WVTR and MC as the responses

\begin{tabular}{|c|c|c|c|c|c|}
\hline \multirow[t]{2}{*}{ Run } & \multicolumn{3}{|l|}{ Variables } & \multicolumn{2}{|l|}{ Responses } \\
\hline & $\begin{array}{l}\text { PNCS } \\
\text { (\% owf) }\end{array}$ & $\begin{array}{l}\mathrm{T} \\
\left({ }^{\circ} \mathrm{C}\right)\end{array}$ & $\begin{array}{l}\text { R.H. } \\
(\%)\end{array}$ & $\begin{array}{l}\text { WVTR } \\
\left(\mathrm{g} \mathrm{m}^{-2} \text { day }^{-1}\right)\end{array}$ & $\begin{array}{l}\mathrm{MC} \\
(\%)\end{array}$ \\
\hline 1 & 1 & 25 & 50 & 2,043 & 4.68 \\
\hline 2 & 3 & 25 & 50 & 2,240 & 5.09 \\
\hline 3 & 1 & 40 & 50 & 5,627 & 5.05 \\
\hline 4 & 3 & 40 & 50 & 5,302 & 5.02 \\
\hline 5 & 1 & 25 & 80 & 938 & 7.35 \\
\hline 6 & 3 & 25 & 80 & 830 & 7.46 \\
\hline 7 & 1 & 40 & 80 & 2,167 & 6.96 \\
\hline 8 & 3 & 40 & 80 & 2,298 & 6.94 \\
\hline 9 & 0 & 32.5 & 65 & 2,750 & 6.25 \\
\hline 10 & 4 & 32.5 & 65 & 2,533 & 6.23 \\
\hline 11 & 2 & 17.5 & 65 & 807 & 7.14 \\
\hline 12 & 2 & 47.5 & 65 & 5,933 & 6.03 \\
\hline 13 & 2 & 32.5 & 35 & 4,714 & 4.74 \\
\hline 14 & 2 & 32.5 & 95 & 327 & 10.03 \\
\hline 15 & 2 & 32.5 & 65 & 2,300 & 5.64 \\
\hline 16 & 2 & 32.5 & 65 & 2,413 & 6.38 \\
\hline 17 & 2 & 32.5 & 65 & 2,543 & 6.25 \\
\hline 18 & 2 & 32.5 & 65 & 2,427 & 6.11 \\
\hline 19 & 2 & 32.5 & 65 & 2,387 & 6.25 \\
\hline 20 & 2 & 32.5 & 65 & 2,533 & 6.27 \\
\hline
\end{tabular}

Moisture content (MC)

Moisture content was measured thermo-gravimetrically, using a moisture analyzer (MS-70, equipped with WinCT-Moisture software, A\&D, Japan). Before drying, each sample is conditioned (under specified conditions of temperature and relative humidity, Table 2) during $24 \mathrm{~h}$ in a climatic chamber. A ramp heating mode was used for drying, programmed to reach the final drying temperature of $105{ }^{\circ} \mathrm{C}$ after 5 min. During the drying process the instrument continually measures the weight of the sample and displays the reduction in moisture. The final moisture content (Eq. 3) is expressed in percentage and represents an average of three readings.

$\mathrm{MC}=\frac{W-D}{W} \times 100$

where: $\mathrm{MC}$ is the moisture content (\%); W is the weight of the material before drying $(\mathrm{g}) ; D$ is the weight of the material after drying $(\mathrm{g})$.
Scanning electron microscopy (SEM)

The surface morphology of modified cotton was determined by scanning electron microscopy. The field emission gun SEM1550 HRSEM (Zeiss, Germany), operating at $5 \mathrm{kV}$, was used. Before the SEM images were taken, the samples were dried in vacuum.

\section{Crease recovery angle (CRA)}

Crease recovery angle was measured according to the ISO 2313/AATCC Test Method 66-2003, using a crease recovery tester (Mesdan S.p.A., Italy). Five rectangular specimens $(40 \mathrm{~mm} \times 15 \mathrm{~mm})$ were cut in warp and weft direction, both on face and back of the fabric. After being conditioned at standard atmosphere, according to SIST EN 20139:1992, half of the test samples were folded face to face, half back to back, and then put into a loading device for $5 \mathrm{~min} \pm 5 \mathrm{~s}$. After the removal of the loading device the sample was transported using tweezers to the specimen holder of the measuring device, being careful not to disturb the existing crease formation. The crease recovery angle was read after $5 \mathrm{~min} \pm 5 \mathrm{~s}$. The results were averaged in warp and weft direction and expressed in degrees.

\section{Whiteness index (WI)}

CIE Whiteness Index value (WI) for each sample was calculated from spectrophotometric measurements, according to AATCC Test Method 110-2005, using X-Rite SpectroEye spectrophotometer (X-Rite, Inc., USA) with the following settings: illuminant D65, UV excluded and CIE 1964 Supplemental Standard Observer (10 degree observer). Each sample was folded twice and the reflectance measured five times. Measurements were averaged and WI values calculated. Prior to testing, all samples were conditioned at standard atmosphere according to SIST EN 20139:1992.

\section{Results and discussion}

A full factorial experimental design was used to determine the influence of temperature, relative humidity and concentration of PNCS microgel on 
water vapour transmission rate (WVTR) and moisture content (MC) of functionalized cotton fabric (Co-PNCS/BTCA). The actual values of independent variables (factors) used for each experiment, as well as the results obtained for both responses (WVTR and MC) are presented in Table 2.

The influence of each factor on final responses (WVTR and MC) was assayed by statistical analysis of variance (ANOVA) (Tables 3, 4). Data obtained from the WVTR and MC was analyzed to fit following polynomial quadratic equations (Eqs. 4 and 5):

$$
\begin{aligned}
\text { WVTR }= & 2422.70-33.69 \times \mathrm{A}+1224.69 \\
& \times \mathrm{B}-1109.94 \times \mathrm{C}-35.37 \times \mathrm{A} \times \mathrm{B} \\
& +18.88 \times \mathrm{A} \times \mathrm{C}-493.62 \times \mathrm{B} \times \mathrm{C} \\
& +46.35 \times \mathrm{A}^{2}+228.48 \times \mathrm{B}^{2}+16.48 \times \mathrm{C}^{2}
\end{aligned}
$$

$$
\begin{aligned}
\mathrm{MC}= & 6.05+0.027 \times \mathrm{A}-0.18 \times \mathrm{B}+1.22 \\
& \times \mathrm{C}-0.071 \times \mathrm{A} \times \mathrm{B}-0.035 \\
& \times \mathrm{A} \times \mathrm{C}-0.15 \times \mathrm{B} \times \mathrm{C}-0.025 \times \mathrm{A}^{2} \\
& +0.062 \quad \times \mathrm{B}^{2}+0.26 \times \mathrm{C}^{2}
\end{aligned}
$$

where the numeric values are the regression coefficients; and $\mathrm{A}, \mathrm{B}$ and $\mathrm{C}$ are the coded independent variables (i.e. factors; see Table 1).

The obtained values of coefficient of determination $\mathrm{R}^{2}$ for both equations were close to $1\left(\mathrm{R}^{2}=0.9959\right.$ in the case of WVTR and $\mathrm{R}^{2}=0.9321$ in the case of $\mathrm{MC})$, thus indicating that a quadratic model developed is statistically valid (i.e. empirical model fits well the actual data) for both WVTR and MC. The lack of fit shown by the $p$ values of 0.0961 (WVTR) and 0.0623 (MC) implies that it is insignificant relative to pure error (Tables 3, 4).

Evaluation of results by ANOVA analysis (Tables 3, 4) showed which model terms can be considered as significant (by having a $p$ value lower than 0.05). Thus, $\mathrm{B}, \mathrm{C}, \mathrm{BC}$ and $\mathrm{B}^{2}$ were significant model terms for WVTR, while $\mathrm{C}$ and $\mathrm{C}^{2}$ were significant model terms for $\mathrm{MC}$. This implies that temperature (factor B) and relative humidity (factor C) had the greatest effect on WVTR, while MC is affected mostly by changes in relative humidity level (factor $\mathrm{C}$ ). The contribution of the concentration of PNCS (factor A) to the final WVTR and MC under the investigated conditions was found to be insignificant $\left(p\right.$ value $_{\mathrm{WVTR}}=0.3537$ and $p$ value $\left._{\mathrm{MC}}=0.8122\right)$ (Tables 3, 4).

The effect of significant model terms is shown in Table 5, listing the coefficient estimates after ANOVA where factors with $p$ value greater than 0.05 were omitted. Standard error is given as an indication of a standard deviation associated with the coefficient estimate. The model term BC in the case of WVTR indicates that there is a significant interaction between temperature and relative humidity; the
Table 3 ANOVA summary for the response surface quadratic model for WVTR

$S S$ refers to the sum of squares, $d f$ refers to the degrees of freedom, and $M S$ refers to the mean squares

\begin{tabular}{llrlrr}
\hline Source & \multicolumn{1}{l}{ WVTR } & \multicolumn{1}{l}{ df } & \multicolumn{1}{l}{ MS } & F value & $p$ value \\
\cline { 2 - 6 } & SS & 9 & $5.226 \mathrm{E}+006$ & 272.22 & $<0.0001$ \\
\hline Model & $4.703 \mathrm{E}+007$ & 1 & $18,157.56$ & 0.95 & 0.3537 \\
$\mathrm{~B}$ & $18,157.56$ & 1 & $2.400 \mathrm{E}+007$ & $1,250.16$ & $<0.0001$ \\
$\mathrm{C}$ & $2.400 \mathrm{E}+007$ & 1 & $1.971 \mathrm{E}+007$ & $1,026.86$ & $<0.0001$ \\
$\mathrm{AB}$ & $1.971 \mathrm{E}+07$ & 1 & $10,011.13$ & 0.52 & 0.4867 \\
AC & $10,011.13$ & 1 & $2,850.13$ & 0.15 & 0.7081 \\
BC & $2,850.13$ & 1 & $1.949 \mathrm{E}+006$ & 101.55 & $<0.0001$ \\
$\mathrm{~A}^{2}$ & $1.949 \mathrm{E}+006$ & 1 & $54,020.26$ & 2.81 & 0.1244 \\
$\mathrm{~B}^{2}$ & $54,020.26$ & 1 & $1.313 \mathrm{E}+006$ & 68.37 & $<0.0001$ \\
$\mathrm{C}^{2}$ & $1.313 \mathrm{E}+006$ & 1 & $6,826.30$ & 0.36 & 0.5642 \\
Residual & $6,826.30$ & 10 & $19,195.78$ & & \\
Lack of fit & $1.920 \mathrm{E}+006$ & 5 & $29,924.20$ & 3.53 & 0.0961 \\
Pure error & $42,336.83$ & 5 & $8,467.37$ & & \\
Cor Total & $4.722 \mathrm{E}+007$ & 19 & & & \\
\hline
\end{tabular}


Table 4 ANOVA summary for the response surface quadratic model for MC

\begin{tabular}{lcrccr}
\hline Source & \multicolumn{7}{l}{ MC } & & & & \\
\cline { 2 - 6 } & SS & df & MS & F value & $p$ value \\
\hline Model & 26.30 & 9 & 2.92 & 15.26 & 0.0001 \\
A & 0.011 & 1 & 0.011 & 0.060 & 0.8122 \\
B & 0.50 & 1 & 0.50 & 2.62 & 0.1364 \\
C & 23.64 & 1 & 23.64 & 123.47 & $<0.0001$ \\
AB & 0.041 & 1 & 0.041 & 0.21 & 0.6544 \\
AC & 0.010 & 1 & 0.010 & 0.052 & 0.8237 \\
BC & 0.18 & 1 & 0.18 & 0.96 & 0.3509 \\
A & 0.016 & 1 & 0.016 & 0.081 & 0.7814 \\
B $^{2}$ & 0.096 & 1 & 0.096 & 0.50 & 0.4954 \\
C & 1.73 & 1 & 1.73 & 9.03 & 0.0132 \\
Residual & 1.91 & 10 & 0.19 & & \\
Lack of fit & 1.57 & 5 & 0.31 & 4.50 & 0.0623 \\
Pure error & 0.35 & 5 & 0.070 & & \\
Cor total & 28.22 & 19 & - & & \\
\hline
\end{tabular}

$S S$ refers to the sum of squares, $d f$ refers to the degrees of freedom, and $M S$ refers to the mean squares

coefficient estimate of the interaction shows an opposite effect than that of temperature which indicates that at low level of relative humidity, temperature has a bigger effect.

The results of statistical analysis show that, when exposed to changes in ambient humidity and temperature, cotton material with incorporated PNCS microgel responds by changes in moisture sorption. Because of the presence of poly-NiPAAm and its thermoresponsiveness, each microgel particle acts as a temperature sensor and actuator. Therefore, at temperatures below the transition temperature, microgel particle is in a swollen state, while it collapses above the transition temperature (Schild 1992; Shibayama and Tanaka 1993), resulting in an increase or decrease of the total MC of modified cotton (Co-PNCS/BTCA). However, it is generally known that ambient moisture concentration is the driving force for moisture absorption. Thus, moisture sorption always increases with an increase of relative humidity (Warner 1994). The same occurs with cotton functionalized with PNCS microgel-the quantity of moisture absorbed by all samples increased with increasing relative humidity, which is confirmed by the positive coefficient estimate value $(\mathrm{C}=1.22$; Table 5). While more moisture gets absorbed by the functionalized cotton when the relative humidity is increasing, at the same time less water vapour gets transmitted through the material, which is confirmed by the negative coefficient value $(\mathrm{C}=-1109.94$; Table 5). According to the coefficient estimate signs and values, a higher WVTR can be expected at higher temperature and lower relative humidity level.

In order to study the interactions between variables, response contour plots were plotted by calculating the WVTR and MC as responses at different levels of any two independent variables while keeping the third variable constant at its centre level. These graphs are shown in Figs. 2, 3, 4, 5, 6 and 7.

Figures 2 and 5 show the relationship between the response variable (WVTR and MC, respectively) and two independent variables (temperature and concentration of PNCS microgel). Since microgel particles are in a swollen state at temperatures below the transition temperature $\left(32.5^{\circ} \mathrm{C}\right)$, they begin to de-swell at temperatures above it, thus permitting the easier passage of water vapour through the fabric. Consequently, at higher temperatures the $\mathrm{MC}$ is lower but WVTR is higher. The shape of contour plots (Figs. 2, 5) indicates that the interaction between temperature and concentration of PNCS microgel is minimal. This means that by increasing the concentration of PNCS microgel we can not expect a further decrease in the MC or increase in WVTR, which is in accordance with the results obtained by ANOVA (i.e. there is no term $\mathrm{AB}$ among significant model terms; Table 5).
Table 5 Effect of significant model terms after ANOVA

\begin{tabular}{lrlllll}
\hline WVTR & & & & MC & \\
$\begin{array}{l}\text { Model } \\
\text { terms }\end{array}$ & $\begin{array}{l}\text { Coefficient } \\
\text { estimate }\end{array}$ & $\begin{array}{l}\text { Standard } \\
\text { error }\end{array}$ & & $\begin{array}{l}\text { Model } \\
\text { terms }\end{array}$ & $\begin{array}{l}\text { Coefficient } \\
\text { estimate }\end{array}$ & $\begin{array}{l}\text { Standard } \\
\text { error }\end{array}$ \\
\hline B & $1,224.69$ & 34.64 & & $C$ & 1.22 & 0.11 \\
$\mathrm{C}$ & $-1,109.94$ & 34.64 & & $\mathrm{C}^{2}$ & 0.26 & 0.087 \\
$\mathrm{BC}$ & -493.62 & 48.98 & & & \\
$\mathrm{~B}^{2}$ & 228.48 & 27.63 & & & & \\
\hline
\end{tabular}




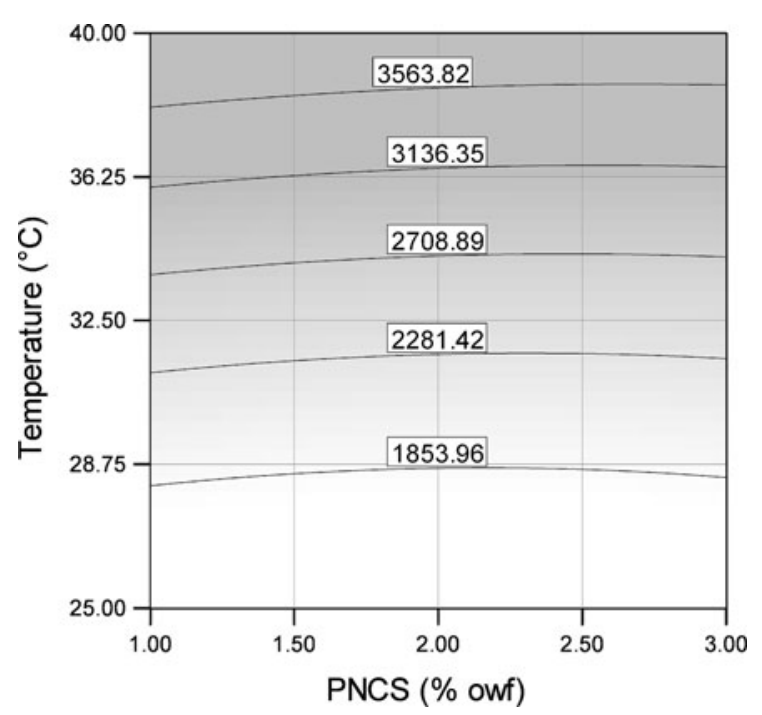

Fig. 2 Influence of temperature and concentration of PNCS microgel on WVTR

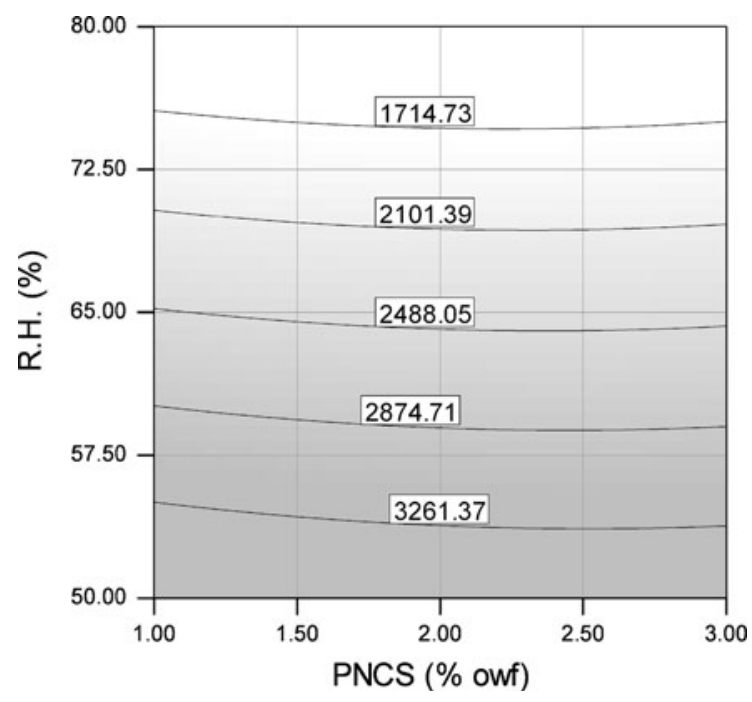

Fig. 3 Influence of relative humidity and concentration of PNCS microgel on WVTR

Figures 3 and 6 show the relationship between the response variable (WVTR and MC, respectively) and another two independent variables (relative humidity and concentration of PNCS microgel). As stated before, the presence of water is the driving force for the microgel responsiveness. Therefore, at higher relative humidity level a lower WVTR but a higher MC can be observed (Figs. 3, 6). Again, the interaction between relative humidity and concentration of

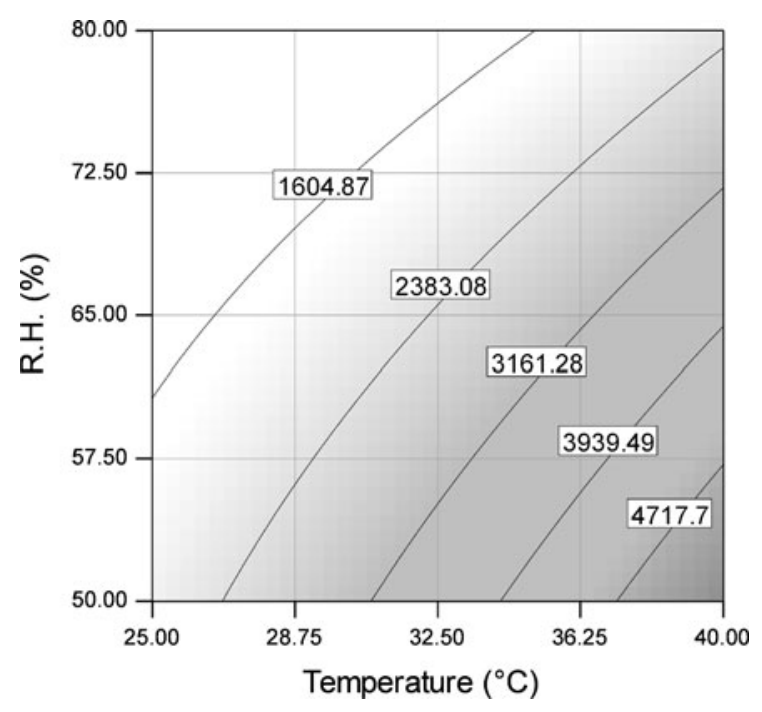

Fig. 4 Influence of relative humidity and temperature on WVTR

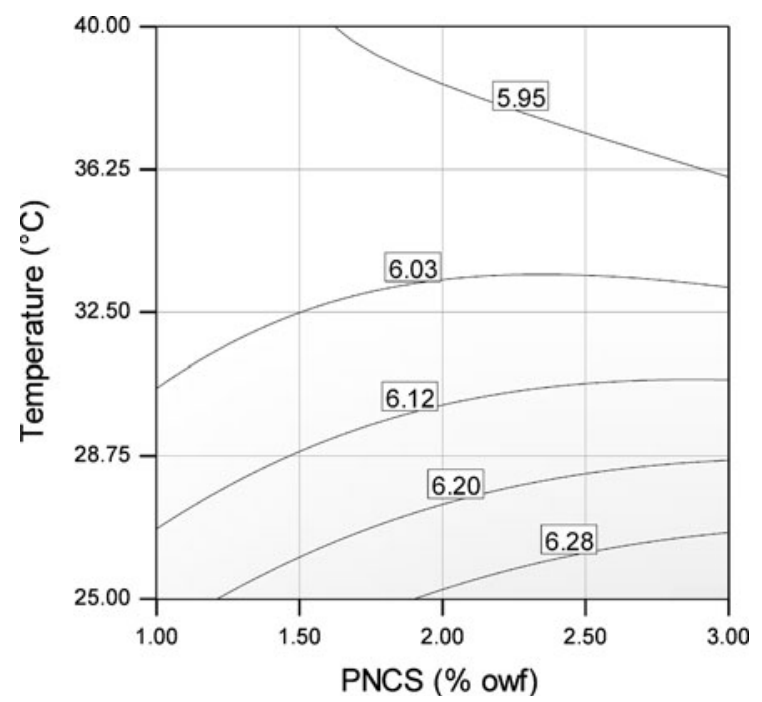

Fig. 5 Influence of temperature and concentration of PNCS microgel on MC

PNCS microgel is found to be negligible, which is in accordance with the results obtained by ANOVA (i.e. there is no term AC among significant model terms; Table 5).

Figures 4 and 7 show the relationship between the response variable (WVTR and MC, respectively) and two most significant independent variables (relative humidity and temperature). As it was expected, the combined effects of temperature and relative humidity 
had the biggest impact on WVTR (Fig. 4), while relative humidity showed the most significant influence on MC (Fig. 7). These findings were already confirmed by ANOVA as all significant model terms listed in Table 5 belonged to factors $\mathrm{B}$ and $\mathrm{C}$, representing temperature and relative humidity. It is interesting to note that specific form of the contour plot on Fig. 4, which differs from all other contour plots, clearly shows the combined influence of relative humidity and temperature on WVTR. By increasing

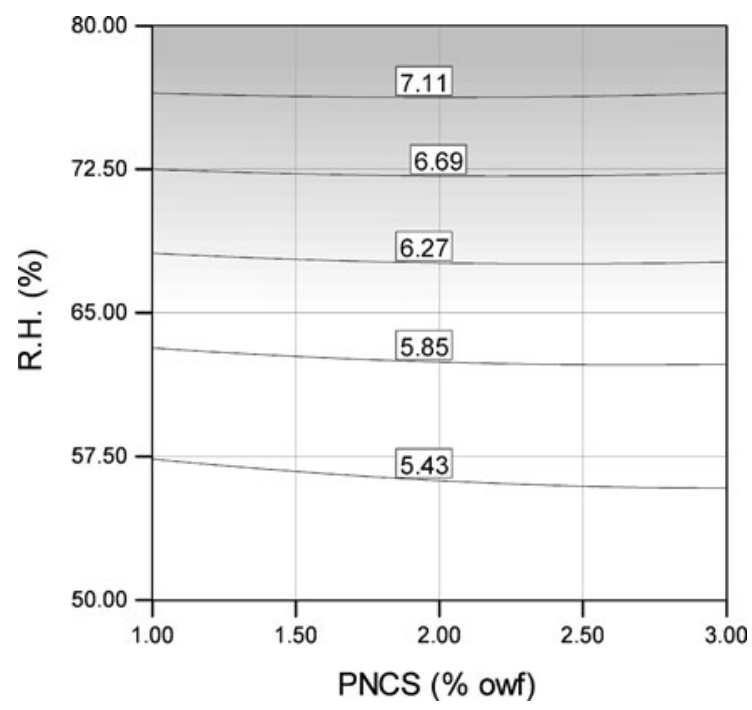

Fig. 6 Influence of relative humidity and concentration of PNCS microgel on MC

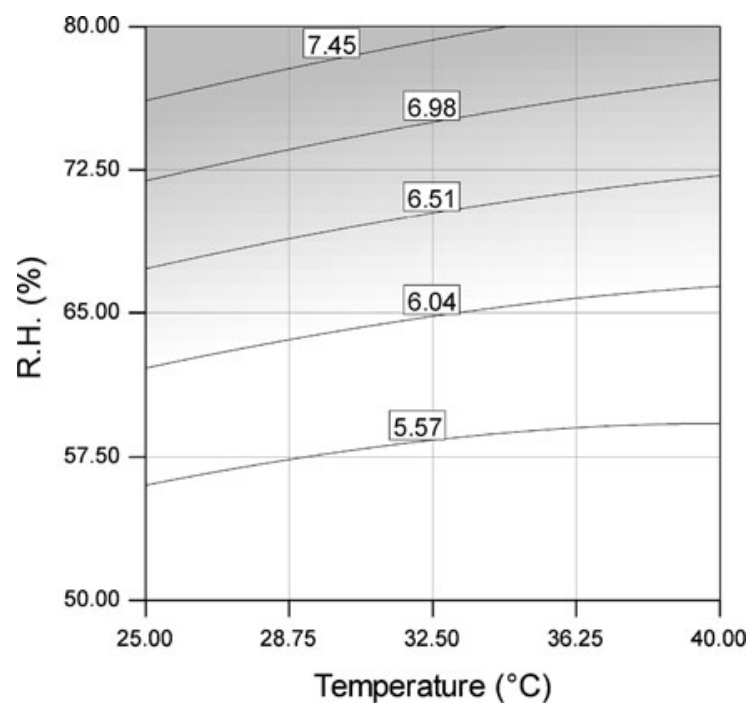

Fig. 7 Influence of relative humidity and temperature on MC the temperature and decreasing the relative humidity WVTR gradually increases, thus clearly showing the effect of PNCS microgel temperature responsiveness.

The regression equations (Eqs. 4 and 5) can be used to predict the WVTR and MC of Co-PNCS/BTCA under the conditions which are different from the ones used in experimental design. An experimental validation was performed by entering the desired operating conditions according to the point prediction optimization. In this case WVTR and MC can be predicted for any fixed variable input, such as desired R.H., temperature or concentration of PNCS microgel within the boundaries of the values chosen for the experimental design. In this way, the model predicts a WVTR or MC output and associated confidence interval. In order to confirm the validity and precision of the model, WVTR and MC were measured at conditions which were not included in the experimental design. The comparison between the values predicted by the central composite design model and values obtained experimentally for WVTR and MC are shown in Tables 6,7 , respectively. The close agreement between the observed and predicted values confirmed the validity of the model.

In order to evaluate the influence of the PNCS microgel incorporation to some other important properties of functionalized cotton fabric, crease recovery and whiteness were also measured. Polycarboxylic acids, such as BTCA are well-known crosslinking agents that can serve as formaldehyde-free durable press finishing agents (Welch 1992; Welch and Andrews 1990). Therefore, since BTCA was used to crosslink PNCS microgel particles and cotton, good crease recovery was expected. However, the presence of PNCS microgel may impart some resistance to crease, depending on the amount applied. The obtained

Table 6 Comparison between WVTR values predicted by the central composite design model and experimentally obtained (actual values) at conditions not included in the experimental design

\begin{tabular}{|c|c|c|c|c|c|}
\hline & \multirow[t]{2}{*}{ PNCS (\% owf) } & \multicolumn{2}{|c|}{$50 \%$ R.H. } & \multicolumn{2}{|c|}{$80 \%$ R.H. } \\
\hline & & $25^{\circ} \mathrm{C}$ & $40{ }^{\circ} \mathrm{C}$ & $25^{\circ} \mathrm{C}$ & $40^{\circ} \mathrm{C}$ \\
\hline \multirow[t]{2}{*}{ Predicted } & 0 & 2,279 & 5,857 & 971 & 2,575 \\
\hline & 2 & 2,059 & 5,496 & 827 & 2,289 \\
\hline \multirow[t]{2}{*}{ Actual } & 0 & 2,223 & 5,800 & 938 & 2,467 \\
\hline & 2 & 2,053 & 5,405 & 803 & 2,298 \\
\hline
\end{tabular}


Table 7 Comparison between MC values predicted by the central composite design model and experimentally obtained (actual values) at conditions not included in the experimental design

\begin{tabular}{llllllll}
\hline & PNCS (\% owf) & \multicolumn{2}{l}{$50 \%$ R.H. } & & \multicolumn{2}{l}{$80 \%$ R.H. } \\
\cline { 7 - 8 } \cline { 7 - 8 } \cline { 7 - 8 } & & & $25{ }^{\circ} \mathrm{C}$ & $40{ }^{\circ} \mathrm{C}$ & & $25^{\circ} \mathrm{C}$ & $40{ }^{\circ} \mathrm{C}$ \\
\hline \multirow{2}{*}{ Predicted } & 0 & 4.82 & 5.06 & & 7.70 & 7.33 \\
& 2 & 5.19 & 5.14 & & 7.92 & 7.26 \\
& 0 & 5.52 & 5.23 & & 7.35 & 7.02 \\
& 2 & 5.64 & 5.27 & & 7.79 & 7.33 \\
\hline
\end{tabular}

results (Fig. 8) show that functionalized cotton fabric (Co-PNCS/BTCA) has a better crease recovery than untreated cotton (Co-UT), meaning that it resists deformation with some rigidness being imparted. In fact, it has been observed that tactile properties

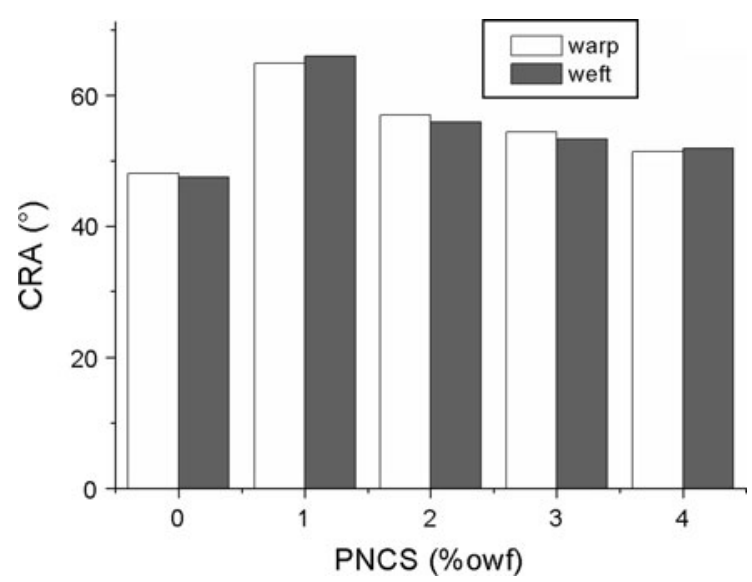

Fig. 8 Crease recovery angles (CRA) of untreated cotton fabric and fabric samples coated with different concentrations of PNCS microgel changed with increased PNCS microgel concentration, resulting in slightly increased stiffness of the fabric. The increase in the stiffness of the fabric is considered a disadvantage, requiring further optimisation.

Even though a known drawback of BTCA usage is a decrease in cotton whiteness (Hebeish et al. 2006), in our case no major influence on whiteness was noticed, regardless of PNCS microgel concentration used. Compared to the untreated sample (WI $=77.32$ ), the WI values of all treated samples only slightly decrease, i.e. from 77.21 (1\% owf PNCS) to 76.33 (4\% owf PNCS) (Krizman Lavric et al. 2010).

Since structural characterization is basic to a thorough understanding of the nature of material and prediction of its characteristics, the surface morphology of cotton with incorporated PNCS microgel was examined by SEM (Fig. 9). SEM micrographs show that the incorporation of PNCS microgel to cotton significantly changes the visual aspect of the fibre surface, where the form, size and amount of microgel particles present is clearly noticeable. In order to see the extent to which the amount of incorporated microgel changes the surface nature of the fibre, the samples with different PNCS concentration levels have been compared. Increasing the amount of the microgel from 1\% owf (Fig. 9a) to 3\% owf (Fig. 9b) shows slightly more microgel particles present on the cotton fibre surface per area square unit. Nevertheless, some filling the spaces between the fibres with the microgel/crosslinker is observable, which should influence the yarn porosity and overall material ability to absorb and transport moisture.

By taking in account the structural characteristics of functionalized cotton material (Co-PNCS/BTCA), the observed effects of thermal and humidity

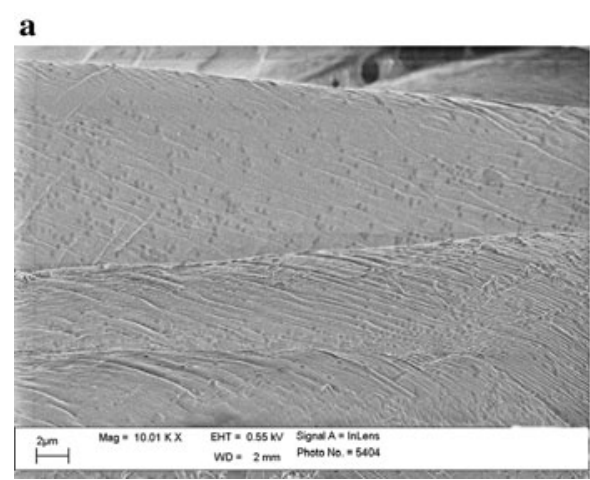

b

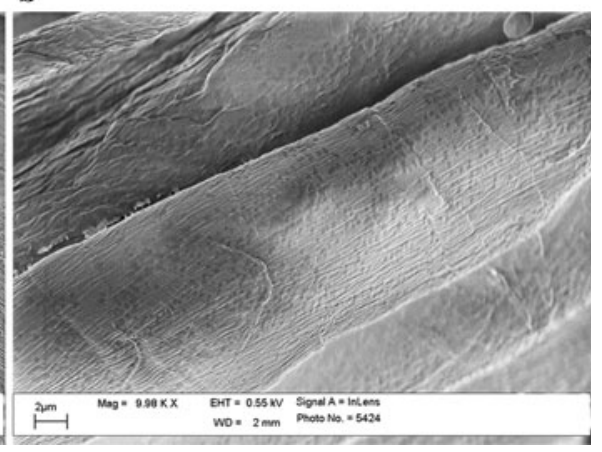

Fig. 9 SEM images of cotton with incorporated $1 \%$ owf (a) and 3\% owf (b) of PNCS microgel 
responsiveness can be clearly explained as the consequence of swelling/collapse of PNCS microgel particles incorporated to the cotton surface. The controlled expansion or contraction of the surface incorporated microgel particles with the variation of temperature leads to moisture management of functionalized material by changing its water vapour transmission rate and moisture content.

The controlled expansion and contraction of PNCS microgel particles with the variation of temperature is the consequence of poly-NiPAAm presence. When rising the temperature over the transition point, polyNiPAAm undergoes collapse transitions with accompanying sharp change in polymer conformation which results from a balance between hydrogen bonding of water onto the chain (hydration at amido groups) and hydrophobic aggregation of isopropyl groups (Schild 1992). The origin of this temperature sensitivity has been fully explained by the cooperative hydration mechanism (Okada and Tanaka 2005). Due to cooperative interaction between the nearest-neighbouring-bound water molecules, sequential hydrogen bonds are formed along the polymer chain. As a result, consecutive sequences of bound water appear along the chain, which leads to a pearl-necklace type chain conformation. When the chain is heated up, the hydrogen bonds are broken and each sequence is dehydrated as a whole, resulting in the sharp collapse of the chain as the consequence of the hydrophobic interactions among the isopropyl groups, which become dominant. As a result, entrapped water molecules via hydrogen bonds in hydrogel are released from the network, leading to de-swelling of PNCS microgel particle. However, because of its hydrophilic nature (which is affected by $\mathrm{pH}$ of the solution), the incorporation of chitosan bearing a large amount of hydrophilic groups including hydroxyl and amino groups into the poly-NiPAAm hydrogel network is expected to greatly influence the above explained interactions. Moreover, when incorporated to cotton, the surface modifying system contains crosslinking agent (BTCA) beside poly-NiPAAm and chitosan (PNCS microgel particles). Thus, both crosslinked structure and the presence of carboxyl groups (from BTCA) in the system are also expected to influence the responsive behaviour of poly-NiPAAm and chitosan.

Since the size of the pores is far more important to moisture transfer than the hydrophilicity (Gibson and Charmchi 1997), it would be expected that at temperatures below transition point the presence of a higher concentration of PNCS microgel particles further decreases the pore size, thus allowing less vapour being transmitted through the fabric. Nevertheless, our study shows that the concentration of PNCS microgel (factor A) does not influence the responsive behaviour of functionalized cotton. This insignificant influence of PNCS microgel concentration might be due to the fact that $1 \%$ owf of PNCS microgel on the cotton surface already covers enough of material surface to ensure responsive behaviour. Any further increase in PNCS microgel concentration does not result in clearly different surface morphology of the functionalized fibre (Fig. 9), so the small differences observed do not reflect in macroscopically observable differences in material responsive behaviour.

All obtained results confirm that the moisture permeability as specific attribute is not present continuously (i.e. passively) on PNCS microgel functionalized cotton, but it could be activated "on demand" by sensing the stimuli (temperature and humidity) in immediate surrounding environment. Apart from the moisture management property assessed in this study, the liquid management property is of great importance for development of stimuli-responsive materials with improved thermal sensation and comfort. Therefore, this property of the functionalized cotton will be thoroughly considered in the subsequent part of this study.

\section{Conclusion}

The use of surface modifying system based on stimuliresponsive microgel was investigated with the aim to implement moisture management properties to cotton fabric since there is a need to adjust the physiological wear comfort in accordance with ambient conditions. Functionalized cotton was prepared by incorporating poly-NiPAAm/chitosan (PNCS) microgel by a paddry-cure method using BTCA as a crosslinker. A central composite design at five levels was employed to carry out the experiments. Three operating factors (temperature, relative humidity and PNCS microgel concentration) were chosen as independent variables, with water vapour transmission rate (WVTR) and moisture content (MC) measured as dependent responses. The results showed that by incorporating 
PNCS microgel to cotton fabric, its moisture content as well as moisture transmission properties can be controlled with small temperature variation in the physiological range. The possibility of prediction of moisture management properties of cotton fabric coated with PNCS microgel has been confirmed. The results are an encouraging step towards the creation of "smart" cotton material with stimuli responsive moisture management properties that can be triggered by varying ambient conditions (or by wearer activity-normal or intensive).

Acknowledgment The financial support provided by Marie Curie Excellence Grant (EXT) project ADVANBIOTEX (MEXT-CT-2006-042641), funded by the EU's Sixth Framework Programme is greatly acknowledged.

Open Access This article is distributed under the terms of the Creative Commons Attribution Noncommercial License which permits any noncommercial use, distribution, and reproduction in any medium, provided the original author(s) and source are credited.

\section{References}

Balakrishnan B, Mohanty M, Umashankar PR, Jayakrishnan A (2005) Evaluation of an in situ forming hydrogel wound dressing based on oxidized alginate and gelatine. Biomater 26:6335-6342

Bischof Vukusic S, Katovic D (2000) Creaseproof finishing using phosphono-based catalyst with polycarboxylic acids. Colour Annual 47:87-94

Box GEP, Draper NR (1987) Empirical model-building and response surface. Wiley, New York

Bruno JS, Vigo TL (1987) Temperature-adaptable textiles containing durably bound polyethylene glycols. Text Res J 57:427-429

Crespy D, Rossi MR (2007) Temperature-responsive polymers with LCST in the physiological range and their applications in textiles. Polym Int 56:1461-1468

Das B, Das A, Kothari VK, Fangueiro R, Araùjo M (2007) Moisture transmission through textiles. Part II: evaluation methods and mathematical modeling. Autex Res J 7(3): 194-216

El-tahlawy KF, El-bendary MA, Elhendawy AG, Hudson SM (2005) The antimicrobial activity of cotton fabrics treated with different crosslinking agents and chitosan. Carbohydr Polym 60:421-430

Gibson PW, Charmchi M (1997) Modelling convection and diffusion processes in porous textiles with inclusion of humidity-dependent air permeability. Int Commun Heat Mass Transf 24:709-724

Gillingham EL, Lewis DM, Voncina B (1999) An FTIR study of anhydride formation on heating butane tetracarboxylic acid in the presence of various catalysts. Text Res J 69:949-955
Harish Prashanth KV, Tharanathan RN (2003) Studies on graft copolymerization of chitosan with synthetic monomers. Carbohydr Polym 54:343-351

Hebeish A, Hashem M, Abdel-Rahman A, El-Hilw ZH (2006) Improving easy care nonformaldehyde finishing performance using polycarboxylic acids via precationization of cotton fabric. J Appl Polym Sci 100:2697-2704

Hipler U-C, Elsner P (2006) Biofunctional textiles and the skin, Curr Probl Dermatol, vol. 33, Burg G (ed), Karger, Basel

Hsieh SH, Lin ES, Wei HC (2006) Effect of chitosan addition to BTCA/CA processed cotton fabrics for adsorbing metallic ions from waste water. J Appl Polym Sci 101:3264-3269

Hsu SC, Don TM, Chiu WY (2002) Synthesis of chitosanmodified poly(methyl methacrylate) by emulsion polymerization. J Appl Polym Sci 86:3047-3056

Huang J, Qian X (2008) Comparison of test methods for measuring water vapor permeability of fabrics. Text Res J 78:342-352

Huang H, Mao Z-P, Yu W-D (2008) Temperature-sensitive composite membranes with "double switch" on water vapor permeability. J Fiber Bioeng Info 1:233-238

Indushekar R, Awasthi P, Gupta RK, Kotresh TM (2005) Studies on test methods used to measure water vapor transmission of fabrics by DSC and conventional dish techniques. J Ind Text 34:223-242

Jocic D, Tourrette A, Glampedaki P, Warmoeskerken MMCG (2009) Application of temperature and $\mathrm{pH}$ responsive microhydrogels for functional finishing of cotton fabric. Mater Technol Adv Perform Mater 24:14-23

Jocic D, Tourrette A, Krizman-Lavric P (2010a) Biopolymerbased stimuli-responsive polymeric systems for functional finishing of textiles. In: Elnashar MM (ed) Biopolymers. InTech, Rijeka, Croatia, pp 37-60

Jocic D, Krizman Lavric P, Warmoeskerken MMCG (2010b) Stimuli-responsive cotton by functional finishing with chitosan/poly-NiPAAm microgel. In: Proceedings of international conference on intelligent textiles (ICIT2010), June 17-18, 2010, Seoul, Korea, pp 15-16

Krizman Lavric P, Warmoeskerken MMCG, Jocic D (2010) Vapour transmission properties of a surface modified textile material with poly-NiPAAm/chitosan microgel. In: Proceedings of 41st international symposium on novelties in textiles (ISNT), 27-29 May 2010, Ljubljana, Slovenia, pp 104-110

Krizman Lavric P, Tomsic B, Simoncic B, Warmoeskerken MMCG, Jocic D (2011) Functionalization of cotton with poly-NiPAAm/chitosan microgel: Part II. Stimuli-responsive liquid management properties. Cellulose (in print).

Kulkarni A, Tourrette A, Warmoeskerken MMCG, Jocic D (2010) Microgel-based surface modifying system for stimuli-responsive functional finishing of cotton. Carbohydr Polym 82:1306-1314

Lee CF, Wen CJ, Chiu WY (2003) Synthesis of poly(chitosan$\mathrm{N}$-isopropylacrylamide) complex particles with the method of soapless dispersion polymerization. J Polym Sci A Polym Chem 41:2053-2063

Li Y (2001) The science of clothing comfort. Text Prog 31(1):1-135

Liu W, Huang Y, Liu H, Hu Y (2007) Composite structure of temperature sensitive chitosan microgel and anomalous 
behavior in alcohol solutions. J Colloid Interface Sci 313:117-121

Männer J, Schuster KC, Suchomel F, Gürtler A, Firgo H (2004) Higher performance with natural intelligence. Lenzinger Ber 83:99-110

Mattila HR (2006) Intelligent textiles and clothing. Woodhead Publishing Limited, Cambridge

McCullough EA, Kwon M, Shim H (2003) A comparison of standard methods for measuring water vapour permeability of fabrics. Meas Sci Technol 14:1402-1408

Mondal S (2008) Phase change materials for smart textiles-an overview. Appl Therm Eng 28:1536-1550

Mondal S, Hu JL (2007) Water vapor permeability of cotton fabrics coated with shape memory polyurethane. Carbohydr Polym 67:282-287

Myers RH, Montgomery DC, Anderson-Cook CM (2009) Response surface methodology, process and product optimization using designed experiments, 3rd edn. Wiley, Hoboken

Okada Y, Tanaka F (2005) Cooperative hydration, chain collapse, and flat LCST behavior in aqueous poly $(N$-isopropylacrylamide) solutions. Macromol 38:4465-4471

Okubayashi S, Griesser UJ, Bechtold T (2005) Moisture sorption/desorption behaviour of various manmade cellulosic fibers. J Appl Polym Sci 97:1621-1625

Orhan M, Kut D, Gunesoglu C (2009) Improving the antibacterial activity of cotton fabrics finished with triclosan by the use of 1,2,3,4-butanetetracarboxylic acid and citric acid. J Appl Polym Sci 111:1344-1352

Rinaudo M (2006) Chitin and chitosan: properties and applications. Prog Polym Sci 31:603-632

Salaün F, Devaux E, Bourbigot S, Rumeaud P (2010) Thermoregulating response of cotton fabric containing microencapsulated phase change materials. Thermochim Acta 506:82-93

Sauperl O, Stana-Kleinschek K (2010) Differences between cotton and viscose fibers crosslinked with BTCA. Text Res J 80:383-392

Sauperl O, Stana-Kleinschek K, Ribitsch V (2009) Cotton cellulose 1,2,3,4-buthantetracarboxylic acid (BTCA) crosslinking monitored by some physical-chemical methods. Text Res J 79:780-791

Schild HG (1992) Poly( $N$-isopropylacrylamide): experiment, theory and application. Prog Polym Sci 17:163-249
Shibayama M, Tanaka T (1993) Volume phase transition and related phenomena of polymer gels. In: Responsive gels: volume transitions I, Dusek K (ed), Springer, Berlin, Germany. Adv Polym Sci 109:1-62

Shin H, Ueda M (1999) Fixation of chitosan on cross-linked cellulose fabrics with polycarboxylic acids. Fiber 55(1): $42-47$

Tourrette A, De Geyter N, Jocic D, Morent R, Warmoeskerken MMCG, Leys C (2009) Incorporation of poly( $N$-isopropylacrylamide)/chitosan microgel onto plasma functionalized cotton fibre surface. Colloids Surf A Physicochem Eng Asp 352:126-135

Vigo TL (1997) Intelligent fibrous substrates with thermal and dimensional memories. Polym Adv Technol 8:281-288

Vigo TL, Hao P, Bruno JS (1992) Multipurpose woven cotton and cotton/polyester blends containing crosslinked polyols affixed by a low temperature cure. Angew Makromol Chem 196(3):1-20

Warner SB (1994) Environmental effects: Solvents, moisture, and radiation. In: Fiber science, Prentice Hall, Upper Saddle River, NJ, pp 102-115

Welch CM (1992) Formaldehyde-free durable press finishes. Rev Prog Color 22:32-41

Welch CM, Andrews BAK (1990) Catalysts and processes for formaldehyde free durable press finishing of cotton textiles with polycarboxylic acids. US patent 4926865

Wollina U, Abdel-Naser MB, Vermac S (2006) Skin physiology and textiles - consideration of basic interactions. In: Biofunctional textiles and the skin, Hipler U-C, Elsner P (eds), Curr Probl Dermatol, Vol. 33, Burg G (ed) Karger, Basel, pp 1-16

Xu W, Shyr T-W (2000) Durable press finishing of cotton fabrics by polycarboxylic acids after graft copolymerization with hydroxyethyl methacrylate. Text Res J 70:8-10

Yang CQ (1993) Infrared spectroscopy studies of the cyclic anhydride as the intermediate for the ester crosslinking of cotton cellulose by polycarboxylic acids. I. Identification of the cyclic anhydride intermediate. J Polym Sci A Polym Chem 31:1187-1193

Yang CQ, Xu L, Li S, Jiang Y (1998) Nonformaldehyde durable press finishing of cotton fabrics by combining citric acid with polymers of maleic acid. Text Res J 68:457-464 